\title{
Designing State Aid Formulas: The Case of a New Formula for Distributing Municipal Aid in Massachusetts
}

\author{
Bo Zhao and Katharine Bradbury
}

\begin{abstract}
This paper designs a new equalization-aid formula based on fiscal gaps of local communities. Using conceptual analysis and simulations with Massachusetts data, the authors illustrate the tradeoffs that policymakers face in deciding on the policy variables in the formula and lay out several general guidelines for setting up these variables. When states are in transition to a new local aid formula, the issue of whether and how to hold existing aid harmless poses a challenge. The authors show that previous studies and the formulas derived from them give differential weights to existing and new aid in filling the gap and hence effectively treat communities receiving greater amounts of existing aid more favorably than communities receiving less or no existing aid. As a fairer alternative, the authors propose a new approach that considers existing and new aid within a consistent framework by taking account of both in filling the gap. In addition, unlike previous research that focuses only on a single year's new aid distribution, the authors simulate the dynamics of aid distributions over multiple years and examine their evolution over time. The authors further provide and compare several possible solutions to addressing the possible tradeoffs between short-term and long-term goals. Although the proposed aid formula is designed for municipal aid and tailored to Massachusetts, the authors note that foundation aid formulas for education implicitly treat existing aid in the same way and suggest that the framework, principles, and policy recommendations might also be applicable to other states designing new municipal aid formulas.
\end{abstract}

JEL Classifications: H70, H73, H77, H83

Keywords: formula design, state aid formula, equalizing aid, fiscal equalization

Bo Zhao is a senior economist in the New England Public Policy Center, and Katharine Bradbury is a senior economist and policy advisor in the Research Department, both at the Federal Reserve Bank of Boston. Their email addresses are bo.zhao@bos.frb.org and katharine.bradbury@bos.frb.org, respectively.

The authors acknowledge excellent research assistance from Jessamyn Fleming, Antoniya Owens, and Ashley Hartman, and very useful discussion with their colleagues on the "research team" of the municipal aid subcommittee of the Municipal Finance Task Force: Alan Clayton-Matthews, Chris Giuliani, Cam Huff, and Pam Kocher. The authors have benefited from participation in meetings of the Subcommittee on Municipal Aid of the Municipal Finance Task Force. They are also grateful to Thomas Downes, Kelly Edmiston, Shihe Fu, Yolanda Kodrzycki, Robert Mohr, Andrew Reschovsky, Pavel Yakovlev, and participants at the National Tax Association's 2007 fall conference for very helpful comments.

This paper, which may be revised, is available on the web site of the Federal Reserve Bank of Boston at http://www.bos.frb.org/economic/wp/index.htm.

The views expressed in this paper are solely those of the authors and are not those of the Federal Reserve System or the Federal Reserve Bank of Boston.

This version: April 28, 2008 


\section{Introduction}

Local governments rely on state aid as a major revenue source. According to the U.S. Census Bureau, intergovernmental revenue from state government accounted for 34.4 percent of local government general revenue nationwide in fiscal year 2005. A large share of these intergovernmental grants (especially education aid) promotes local fiscal equalization. The literature has long recognized that there are disparities in local governments' ability to provide a standard quality and quantity of public services with reasonably uniform tax burdens (for example, Bradbury, Ladd, Perrault, Reschovsky, and Yinger 1984, Yinger 1986, and Chernick 2004 in the non-U.S. context). Without aid to correct such disparities, otherwise identical individuals or firms would have to pay different amounts of taxes for a given level of public services or receive different levels of services for the same amounts of taxes, simply because they are located in different communities (Downes and Pogue 1994, 2002). This violates the fair compensation standard proposed by Yinger (1986), who states that "no citizen should be worse off simply because he or she lives in a city with high costs and/or low resources." Beyond this equity justification, there is an efficiency argument for equalization: In the presence of fiscal disparities, individuals and firms have incentives to move from one community to another, potentially resulting in resource allocation distortion and efficiency loss when moving costs are taken into account. In addition, fiscal disparities impose certain advantages and disadvantages on localities and may create unfair competition among them. ${ }^{1}$

${ }^{1}$ See Downes and Pogue (2002) for further discussions about the various objectives of intergovernmental grants. 
A large portion of state aid is distributed through formulas. Louis, Jabine, and Gerstein (2003) state that a formula based on selected principles or rationales provides a mechanism for addressing some targeting issues. Since such a formula distributes aid with a certain degree of transparency, it helps to build consensus and enhances the credibility of an intergovernmental program. Considering the importance of aid formulas, however, their design is still an underexplored subject. Previous studies such as Gonzalez (1980), Spencer (1982), Bogart and Erickson (1989), Jabine, Louis, and Schirm (2001), Louis, Jabine, and Gerstein (2003), Martinez-Vazquez and Boex (2006), and Martinez-Vazquez and Searle (2007) consist mostly of qualitative or descriptive analyses of factors, data, statistical estimation approaches, and special features used in the formulas. Bradbury et al. (1984), Ladd and Yinger (1994), and Downes and Pogue (1994, 2002) discuss the general design of aid formulas; however, as we elaborate in the paper, they do not offer a consistent framework for considering existing and new aid when states are in transition to a new local aid formula. Bogart and Erickson (1989) note, “... one rarely gets to design an intergovernmental grants system from scratch. In general, there is a system already in place, which is to be replaced or modified." Even when the state government's objective is to create a new, separate aid program, explicit legislation or tradition usually prevents it from taking away aid dollars from existing programs. Therefore, the question of whether and how to "hold harmless" existing aid poses a challenge to the design of a new aid formula.

This paper contributes to the literature by proposing a new approach that takes account of existing and new aid within a consistent framework. Following Bradbury et al. (1984), Ladd, Reschovsky, and Yinger (1991), and Ladd and Yinger (1994), we measure fiscal disparities as gaps between the costs that local governments must incur to provide a standard quality and 
quantity of local public services ("costs") and the ability of these governments to raise revenue from local resources ("local revenue capacity"). In previous studies (for example, Bradbury et al., 1984, and Ladd, Reschovsky, and Yinger, 1991) and the local aid formulas derived from them (the Minnesota Local Government Aid formula and a now-defunct aid formula in Massachusetts), existing aid is subtracted from each community's local cost-capacity gap (by being added to local revenue capacity), while new aid fills a portion of the rest of the gap. As we show in the paper, this approach is conceptually inconsistent because it gives differential weights to existing and new aid dollars in filling the gap. As a result, it effectively gives favorable treatment to communities receiving more existing aid compared with those receiving less or no existing aid. As a fairer alternative, we propose a new approach that considers existing and new aid together in filling the local gap.

In addition to conceptual analyses - the central focus of previous research-we use simulations based on Massachusetts data to examine policy tradeoffs and present applicable guidelines for setting the policy variables in the formula. Unlike previous studies that focus only on a single year's new aid distribution, we simulate the dynamics of aid distributions over multiple years and examine the evolution of these distributions over time. Recognizing possible tradeoffs between short-term and long-term goals, we compare several solutions to addressing these tradeoffs.

We use Massachusetts as an example because its cities and towns are in urgent need of a new municipal (non-school) aid formula. The current general aid formulas in Massachusetts either are obsolete or do not well target needier communities (Bradbury and Zhao 2006). Facing long-term structural fiscal difficulties, Massachusetts cities and towns are seeking additional 
non-school aid from the state government, but substantial increases in state appropriations are unlikely in the absence of a new formula (See Municipal Finance Task Force 2005 and Bluestone, Clayton-Matthews, and Soule 2006). Therefore, new research in aid formula design could significantly benefit Massachusetts municipalities. The new aid formula presented in this paper is designed for municipal (non-school) aid in Massachusetts, but its framework, principles, and policy recommendations are sufficiently general to be applied to education aid and to other states designing new aid formulas.

\section{Basic framework}

This paper focuses on designing an aid formula that helps to equalize the ability of cities and towns to provide standard municipal services. ${ }^{2}$ Providing the basis for the new formula, Bradbury and Zhao (2006) measure that ability by assessing the gap between communities' municipal costs and non-school local revenue capacity. Measures of both costs and capacity are based on local social and economic characteristics that city or town governments cannot directly influence in the medium term, controlling for quality and quantity of local services, local preferences, and other confounding factors. ${ }^{3}$ Using these "uncontrollable" cost and capacity factors avoids giving local governments incentives to change their behavior in order to receive

\footnotetext{
2 Some state aid formulas may not have a goal of achieving fiscal equalization and thus should be designed differently. For example, Gottlieb (2006) describes how to design a state aid system to achieve desirable land use objectives within U.S. states.

${ }^{3}$ Bradbury and Zhao (2006) assume average efficiency for each community when estimating cost and capacity. Like other researchers, they have no data to control directly for the efficiency of production processes that local governments choose in supplying local services. However, they argue that there is no reason to believe that such choices are correlated with their cost variables and hence biasing the estimated coefficients.
} 
more aid. These authors show that per capita municipal costs of Massachusetts communities increase with population density, population size, jobs per capita, and rates of unemployment and poverty. On the revenue capacity side, they take account of the constraints of local tax limitations by modeling them as a function of residents' incomes and find that local governments in higher-income communities have greater ability to tap into their residential property tax base and thus are less constrained by the local property tax limitation. Bradbury and Zhao (2006) also incorporate measures of nonresidential property tax capacity and subtract statutorily required contributions or payments for non-municipal purposes in tallying nonschool local revenue capacity. The relative size of per capita cost-capacity gaps across communities reflects "the additional spending that a jurisdiction must undertake to achieve the same level of services as some baseline jurisdiction" relative to "the additional sacrifice that a jurisdiction must make to raise the same revenue as a baseline jurisdiction" (Bradbury et al. 1984).

\section{A gap-based equalization aid formula}

We start with a basic gap-based formula framework that follows Bradbury et al. (1984). ${ }^{4}$ This basic framework does not consider other existing state aid programs or the previous year's aid distributions, but we will return to the subject of how to treat existing aid in Section II. To address local fiscal disparities and also consider various policy and political factors, the formula

\footnotetext{
${ }^{4}$ Some alternative formula frameworks are not gap-based. For example, aid can be distributed proportionally to costs only or inversely to local revenue capacity (as in the Massachusetts lottery aid formula). The state government can also choose to take an average of the aid distributions from the two methods or allow cities and towns to pick whichever gives them larger aid amounts. Policymakers should decide which approach is appropriate, based on the circumstances of their individual state and their policy needs.
} 
allocates aid in proportion to the measured local cost-capacity gap, with three built-in policy variables: the total aid pool, the minimum per capita aid, and the baseline per capita gap. Minimum per capita aid is an aid floor, which guarantees that no communities will receive less than a specified amount of aid dollars per capita. ${ }^{5}$ Policymakers can choose to set minimum aid at zero, but the provision of nonzero minimum aid addresses the political need to benefit all communities and win their support, regardless of their fiscal condition. However, positive minimum aid obviously interferes with the achievement of equalization among cities and towns. ${ }^{6}$

The baseline gap is a gap threshold, above which communities are eligible to receive aid in proportion to the differences between their individual gaps and the baseline gap. The formula needs a baseline gap because the statewide distribution of cost-capacity gaps may be wide and may involve negative gaps; it is practically impossible to distribute aid simply in proportion to the gap without setting a benchmark or a new "zero" point. With the inclusion of a baseline gap in the formula, communities with per capita gaps lower than the baseline gap receive the minimum-aid amount by design.

This gap-based aid formula can be written in symbols as follows. Per capita aid to community $k, A_{k}$, is

$$
\begin{aligned}
A_{k} & =\max \left(M, r \times\left(G_{k}-G^{*}\right)\right) \\
& =r \times\left(G_{k}-G^{*}\right) \text { for communities with } G_{k}>G^{*} \text { and } r \times\left(G_{k}-G^{*}\right)>M, \text { or }
\end{aligned}
$$

${ }^{5}$ Minimum aid is also called "base aid" or "basic aid" in some state aid formulas (for example, the Minnesota Local Government Aid formula).

${ }^{6}$ Some policymakers may even consider having a per capita aid ceiling in addition to the aid floor. This would add more complexity to the formula and further interfere with the equalization goal. 


\section{$=M$ for all other communities,}

where $G_{k}$ is the per capita cost-capacity gap in community $k, G^{*}$ is the baseline per capita gap, $r$ is a fraction of the relative gap $\left(G_{k}-G^{*}\right)$ that the aid dollars fill, and $M$ is minimum per capita aid. To simplify and differentiate, we call $A_{k}$ "equalizing aid" when it is greater than $M$ and "minimum aid" otherwise.

The fraction $r$, which is a constant across equalizing-aid recipients, can be calculated with the following equation:

$$
\sum_{i} A_{i} N_{i}+\sum_{j} M N_{j}=T A
$$

where $T A$ is the statewide total aid pool, $N$ is the community population, $i$ is an index for equalizing-aid recipients, and $j$ is an index for minimum-aid recipients. After solving the equation, we obtain

$$
r=\frac{T A-M \sum_{j} N_{j}}{\sum_{i}\left(G_{i}-G^{*}\right) N_{i}} \text { and } A_{i}=r \times\left(G_{i}-G^{*}\right)=\frac{T A-M \sum_{j} N_{j}}{\sum_{i}\left(G_{i}-G^{*}\right) N_{i}} \times\left(G_{i}-G^{*}\right) .
$$

The numerical calculations often involve multiple iterations to ensure that $A_{i}>M$ for equalizing-aid recipients. Since the aid function is continuous, the equalizing-aid communities with the lowest gaps receive only slightly more than the minimum aid per capita. ${ }^{7}$ Figure 1 shows how aid is distributed according to this formula.

${ }^{7}$ Both Gonzalez (1980) and Spencer (1982) emphasize that it is important to have a gradual transition between tiered aid allocations in order to minimize the effects of small data errors. 
This gap-based formula is fairly similar to a foundation education aid formula, various forms of which are in use in 41 states (Huang 2004, Table B.3). A typical foundation formula can be written in symbols as:

$$
A_{k}=F_{k}-\left(t^{*} \times R_{k}\right)
$$

where $A_{k}$ is the per-pupil foundation aid for school district $k, F_{k}$ is the per-pupil foundation spending for that district, which is often a statewide per-pupil foundation amount, $F^{*}$, adjusted for inter-district cost differentials, and $\left(t^{*} \times R_{k}\right)$ is the district's revenue capacity, measured as a state-specified tax rate, $t^{*}$, multiplied by the local tax base, $R_{k}$.

Both formulas are aiming to fill a gap-the difference between per-pupil foundation spending and capacity in the foundation formula and the per-capita relative gap $\left(G_{k}-G^{*}\right)$ in the gap-based formula - and both use state aid to do so. In most states, the foundation formula is written - and funds are appropriated - so that state aid fills the entire gap; notice that there is no " $r$ " in the foundation formula above, as aid is the entire difference between the two gap elements. Ladd and Yinger (1994) show that the foundation formula is a special case of the gapbased formula under the condition that $r=1 .{ }^{8}$ Although $r$ is theoretically set equal to one in the foundation formula, this is not always the case in practice. Downes and Pogue (2002) suggest that the state government may attempt to limit its budgetary liability by choosing too low a target level of spending $\left(F^{*}\right)$ or too high a state-specified tax rate $\left(t^{*}\right)$ and therefore too

${ }^{8}$ Ladd and Yinger also note that a gap-based formula equivalent to a foundation formula would implicitly assume that service quality is set at the minimum acceptable level and that $G^{*}=0$, meaning that communities able to afford the foundation amount at the statewide tax rate receive zero aid; however, in practice, many foundation formulas also include minimum aid for less needy communities. 
high a measured local capacity. In that case, foundation aid would fill only a portion of the actual gap between the true foundation spending and the true local capacity.

\section{Policy tradeoffs}

The three policy variables $-T A, M$, and $G^{*}$-all affect $r$ as well as the gap level on the margin between equalizing and minimum aid, that is, the kink point in Figure 1 (although the latter effect is not expressible in closed form). Since $r$ is the fraction of the gap filled by equalizing aid, it can be interpreted as an indicator of equalization - the degree to which aid is focused on the neediest communities:

$$
\frac{\partial r}{\partial T A}>0, \frac{\partial r}{\partial M}<0, \text { and } \frac{\partial r}{\partial G^{*}}>0
$$

A larger fraction of the relative gap will be filled by equalizing aid-hence achieving a higher degree of equalization - if the state provides more aid funds (TA), sets minimum aid $(M)$ at a lower level, or sets the baseline gap $\left(G^{*}\right)$ at a higher level. With the opposite policy choices, communities with lower gaps will receive more aid, thus sharing funds more broadly. Figures 2 to 4 illustrate conceptually the impact on the aid distribution of changing each policy variable.

There are two special cases in this formula in terms of the value of $r$. The first occurs when $r=0$, which means that no equalization is achieved. This would require minimum aid $M$ high enough to equal the statewide average per capita aid. Then every community would be a minimum-aid recipient, and aid would be distributed simply on a per capita basis. In a survey of existing general-purpose local aid formulas of the 50 states conducted in the spring of 2006, we found that most existing state aid formulas used this per capita aid approach. 
The other special case occurs when $r=1$ and $M=0$. This implies that $\sum_{i}\left(G_{i}-G^{*}\right) N_{i}=T A$ for aid recipients, from which we can numerically search for the solution for $G^{*}$ and the number of communities receiving aid. In this case, state aid fills the entire relative gap $\left(G_{i}-G^{*}\right)$ for every aid recipient. It is practically equivalent to a "top-down" approach; that is, state aid is given out in order of gap magnitude. The community with the largest gap is the first to receive an amount of state aid large enough so that its gap net of aid equals that of the community with the second largest gap. Then these two communities equally receive per capita aid until their gaps net of aid equal that of the community with the third largest gap. This process continues until all aid recipients' gaps net of aid are brought down to the level of the baseline gap. By distributing aid this way, the state government focuses aid exclusively on the communities with largest gaps, which by our definition are the neediest ones. In this sense, one may consider this top-down approach completely equalizing. ${ }^{9}$ However, this approach has a serious shortcoming: Closing all relative gaps can be very costly. Given a limited aid pool, aid dollars could be depleted very fast after filling the top gaps, leaving no aid for the rest of the communities. Analysts and policymakers alike might debate the meaning of "equalizing" when many high-gap communities would receive no aid so that all aid funds could be focused on the very highest-gap communities.

We can further explain the policy tradeoffs involved in the general gap-based formula using Massachusetts data. Table 1 presents summary statistics of the per capita municipal costs,

\footnotetext{
${ }^{9}$ By contrast, whenever $r$ is less than one, communities with larger gaps are left with larger net-of-aid gaps in per capita dollar terms, even though they also receive more aid dollars per capita than do communities with smaller gaps.
} 
non-school local revenue capacities, and gaps for Massachusetts cities and towns in 2005, as measured by Bradbury and Zhao (2006). The wide variations in cost-capacity gaps indicate that there are large fiscal disparities across Massachusetts communities. To simulate running the formula, we start with a set of policy variable values: total aid pool of $\$ 275$ million, minimum per capita aid of $\$ 10$, and baseline per capita gap of $\$ 244$. The $\$ 275$ million aid pool is close to the five-year average of new aid increments proposed by the Massachusetts Taxpayers Foundation (2005 and 2006). ${ }^{10}$ The $\$ 10$ minimum per capita aid is about a quarter of the statewide aid pool per capita, given that the 2004 population in Massachusetts was over 6 million. The $\$ 244$ baseline gap is the $25^{\text {th }}$ percentile of the gap distribution, so choosing this value makes three-quarters of Massachusetts communities eligible for equalizing aid. We then change each of the policy variable values, one at a time, in three alternative scenarios (Table 2). The outcomes resulting from the changes are consistent with what the framework predicts (Figures 2-4). Communities with larger gaps receive more aid in the scenarios with higher degrees of equalization. ${ }^{11}$

General guidelines for setting the policy variables

The tradeoffs faced by policymakers make it very difficult for them to decide on values for the policy variables. While the literature does not offer systematic, applicable principles for

\footnotetext{
${ }^{10}$ Massachusetts Taxpayers Foundation (2005 and 2006) proposes that the statewide new aid pool increase by \$159 million, \$210 million, \$263 million, \$324 million, and \$384 million for years 2007 to 2012 in order to bring the major local aid programs to the average historic level of 40 percent of state growthtax revenues (personal income, sales and use, and corporate excise) with a ten-year phase-in schedule.

${ }^{11}$ In the extreme "top down" case of selecting the baseline gap so that $r=1$ with zero minimum aid and the total aid pool of $\$ 275$ million (as in the other simulations), we find that only the 24 highest-gap communities (of the 351 Massachusetts cities and towns) would receive aid, with per capita equalizingaid amounts ranging from $\$ 8$ to $\$ 439$.
} 
choosing values for the policy variables, we lay out several guidelines that may assist policymakers in balancing the involved tradeoffs.

If policymakers decide to choose a nonzero minimum aid, they may consider setting it as a constant percentage of the statewide average per capita aid pool, with the size of that percentage determined by the state's emphasis on equalization. When there is no change in individual gaps and the baseline gap, setting minimum aid this way helps to ensure that (1) changes in the statewide population and total aid pool will have a similar impact on minimumaid recipients and equalizing-aid recipients; and (2) there will be a stable portion of the total aid pool available for both equalizing aid and minimum aid.

When choosing a baseline per capita gap, policymakers may consider what share of communities should be eligible for equalizing aid. For example, if the state wants half of the communities to be eligible, it should choose a baseline gap just below the median. Note that eligibility itself does not guarantee the receipt of equalizing aid. Whether a community with a per capita gap higher than the baseline gap receives equalizing aid also depends on the level of minimum per capita aid and the total aid pool.

Policymakers should avoid choosing a baseline gap that is so high that very few communities receive equalizing aid, since that would make it difficult to win broad local support for the aid program. Policymakers should also avoid treating zero as a default baseline gap. As Bradbury and Zhao (2006) argue, the gap calculation can be used to measure the relative fiscal disadvantage of communities, but its zero point has very little or no absolute normative meaning. Because the measurement and calculation of both costs and capacity involve some 
uniform but arbitrary scaling, the zero point reflects the scaling values that are used, not an actual balance between costs and capacity.

Setting the size of the aid pool requires a balance between responsiveness to local needs and other claims on the state government's resources. On the one hand, the state can choose to commit a fixed amount of funding to aid, which would provide predictability to the aid distribution and make it easier for municipalities to set their budgets for the following year. However, such fixed funding may not be responsive to changes in either local needs or the state's budget situation. Thus, the state may consider indexing the size of the aid pool to population changes, inflation rates, and/or other changes in local needs, or it may link the aid pool to growth in selected state revenue sources. ${ }^{12}$ Linking to state revenue sources ties local aid directly to fluctuations in the state's fiscal health caused by the business cycle and other factors, but observers note that local aid has often faced larger than proportional cuts when states run into fiscal difficulties, so sharing proportionally in state revenue fluctuations may represent an improvement in the stability of local aid. ${ }^{13}$

The goal of achieving a certain degree of equalization ultimately directs the selection of the three policy variables. Because all these variables together affect the degree of equalization, none can be determined without considering the others. Policymakers may need to explore

12 For example, Massachusetts Taxpayers Foundation (2005) has proposed that the state dedicate 40 percent of state growth-tax revenues (personal income, sales and use, and corporate excise) to local aid. The Massachusetts Municipal Association (2006) has also suggested that 10 percent of that 40 percent be directed to a new municipal aid account. These numbers are close to the average historic levels before Massachusetts cities and towns experienced substantial local aid cuts during the last recession.

${ }^{13}$ Many states experienced fiscal crises and significantly cut their aid to local governments after the 2001 recession. Dye and Reschovsky (2008) find that on average school districts increased property taxes by 23 cents in response to each dollar cut in state aid. 
different combinations of policy variable values and compare the resulting aid distributions in order to select a preferred set of policy choices.

\section{Alternative Treatments of Existing Aid When Hold Harmless Applies}

Similar to much of the formula design literature that focuses on developing aid formulas "from scratch," the basic gap-based formula we have described does not consider other existing state aid programs or the previous year's aid distributions. But in reality most states have in place some existing programs providing aid to local governments and may face transition difficulties when developing and introducing a new formula (Bogart and Erickson 1989). Existing aid programs may be aimed at goals different from those of the new program. Alternatively, they may have a similar equalization goal but reflect former years' measures of "need" (aid-worthiness). They may be held harmless by tradition or explicit legislation that guarantees past dollar amounts of aid in future years.

Just as for existing aid, once a new formula is enacted, decisions must be made about whether and how the previous year's aid dollars will be accounted for in determining the current year's aid distribution. Many states hold local aid distributions harmless by retaining the previous year's aid dollars for each community and running the formula to allocate only any new aid dollars added that year. That is, aid distributed to each community in year two is equal to the sum of year-one aid plus new year-two aid. Bradbury et al. (1984) argue that an approach without a hold-harmless provision could result in a high degree of equalization, but could also lead to significant, abrupt year-to-year changes in aid. The hold-harmless provision allows future distributions of new aid funds to change in line with current objectives, but 
avoids the disruption of local budgets that might result from taking existing funds away from communities. ${ }^{14}$ This avoidance of negative changes in aid amounts must be traded off against proportionality of total current-year aid to current measures of need.

In this section of the paper we use a consistent framework in examining three alternative approaches, including two "standard" approaches and one new approach, that can be used in accounting for existing aid in determining the distribution of new aid, assuming that this existing aid is held harmless or guaranteed in future years and similarly for dollars distributed in year $t$ as new aid is calculated in year $t+1$.

In a sense, one can interpret the three approaches presented below as involving different definitions of what it means to hold existing or prior-year aid harmless. While all three guarantee individual communities a continuation of the existing aid amount and at least the "minimum" amount of new aid, the first standard approach takes an entirely "hands-off" view of existing aid by ignoring it (its amount has no effect on current-year new aid); the second standard approach acknowledges that existing aid supplements revenue capacity (and implicitly counts a fraction of it toward filling the current-year gap); and the third, new, approach provides new aid beyond the minimum only after considering how much of the gap is filled by existing aid-it treats existing and new aid as completely interchangeable in filling the current gap-and is therefore able to achieve greater equalization in relation to the gap.

\footnotetext{
${ }^{14}$ Downes and Pogue (2002) note that hold-harmless provisions can also be seen as a way to shield communities "from the effects of errors in measurement of inputs to the aid formula" (p. 348). This is the case when the previous year's distribution suffers less from measurement error than do the current-year formula elements, or when holding harmless multiple years of past aid smoothes errors.
} 
First approach: ignore existing aid

The simplest approach to treating existing aid-whether existing aid received by communities for other purposes or previous-year aid - is to take no account of it in determining current-year new aid. That is, the new and existing aid programs are considered totally independent of each other. One example of such a distribution formula is Special Education Grants to States (CDFA \#84.027), in which a state's new aid funds in a given year depend only on the number of children and the number of poor children who are within the age range for which the state mandates services to children with disabilities: each state's total aid is equal to the sum of new aid and FY1999 aid (held harmless).

In the first approach, community $k$ 's new aid is distributed as described in Section I above, and its combined (existing and new) aid $C A_{k}$ is calculated as

$$
\begin{aligned}
C A_{k}= & A_{k}+E_{k} \text { where } E_{k} \text { is community } k \text { 's aid dollars received from other aid } \\
& \text { formulas (existing aid) or in the previous year, } \\
= & M+E_{k} \text { if community } k \text { receives minimum aid, or } \\
= & r_{1} \times\left(G_{k}-G^{*}\right)+E_{k} \text { if community } k \text { receives equalizing aid. }
\end{aligned}
$$

In this approach, a community receives minimum aid if $M>r_{1} \times\left(G_{k}-G^{*}\right)$. Furthermore, the fraction of the relative gap filled is

$$
r_{1}=\frac{\left(T A-M \sum_{j} N_{j}\right)}{\left(\sum_{i} N_{i}\left(G_{i}-G^{*}\right)\right)^{\prime}}
$$


where $j$ subscripts minimum-aid communities and $i$ subscripts communities receiving equalizing aid.

Second approach-treat existing aid as addition to local capacity

A more common approach is to treat existing or prior-year aid dollars like other revenues as part of revenue capacity, essentially subtracting them from the cost-capacity gap. This is the approach used in several previous studies (for example, Bradbury et al., 1984, and Ladd, Reschovsky, and Yinger, 1991) and the local aid formulas derived from those studies (the Minnesota Local Government Aid formula and the now-defunct additional assistance formula in Massachusetts). When existing aid is subtracted from the local fiscal gap, new aid fills a portion of the rest of the gap. In this context, per capita new aid to community $k, A_{k}$, is calculated as

$$
A_{k}=\max \left(M, r_{2} \times\left(G_{k}-G^{*}-E_{k}\right)\right),{ }^{15}
$$

where $r_{2}$ is the fraction of the relative gap, net of existing aid, that is filled by this second approach and

$$
r_{2}=\frac{\left(T A-M \sum_{j} N_{j}\right)}{\left(\sum_{i} N_{i}\left(G_{i}-G^{*}-E_{i}\right)\right)} .
$$

Community $k$ 's combined general purpose aid per capita, $C A_{k}$, is then calculated as

15 The first and second approaches can be seen as the polar cases of a formula $A_{k}=\max \left(M, r \times\left(G_{k}-G^{*}-\lambda E_{k}\right)\right)$, where $0 \leq \lambda \leq 1$. We are grateful to Robert Mohr for pointing out this generalization. 


$$
\begin{aligned}
& C A_{k}=A_{k}+E_{k} \\
& =M+E_{k} \text { if community } k \text { receives minimum aid, or } \\
& =r_{2} \times\left(G_{k}-G^{*}-E_{k}\right)+E_{k} \text { if community } k \text { receives equalizing aid. }
\end{aligned}
$$

In this case, a community receives minimum aid if $M>r_{2} \times\left(G_{k}-G^{*}-E_{k}\right)$.

For equalizing communities, the expression for $C A_{k}$ can be rearranged as follows:

$$
C A_{k}=r_{2} \times\left(G_{k}-G^{*}\right)+\left(1-r_{2}\right) \times E_{k}
$$

Comparing this expression with combined aid for equalizing communities under the first approach, $C A_{k}=r_{1} \times\left(G_{k}-G^{*}\right)+E_{k}$, indicates that the second approach allows the state government to focus somewhat more aid on equalization. By giving less new aid to communities with high levels of existing aid, the state can cover a higher proportion of the relative gap. If no communities switch between minimum aid and equalizing aid, the numerators in the expressions of $r_{2}$ and $r_{1}$ are equal, and the denominator in the $r_{2}$ expression is smaller, so $r_{2}>r_{1}$. Moreover, some communities may switch from equalizing aid to minimum aid, because they have positive relative gaps but relatively large amounts of existing aid. If so, their new aid $(M)$ is smaller and more funds are available for the remaining equalizing-aid communities, further raising $r_{2}$.

Under the second approach, $\frac{\partial A_{k}}{\partial E_{k}}<0$ for equalizing-aid communities, while new aid is invariant to existing aid in the first approach (which ignores it). Thus, communities with large amounts of existing aid receive relatively less new aid with the second approach than with the first. That is, 
when $E_{k}>\left(1-\frac{r_{1}}{r_{2}}\right) \times\left(G_{k}-G^{*}\right)$, then

$r_{2} \times\left(G_{k}-G^{*}-E_{k}\right)<r_{1} \times\left(G_{k}-G^{*}\right)$ for these communities, even though $r_{2}>r_{1}$.

Third approach-existing aid helps fill the gap

A third approach is to consider existing aid along with new aid in filling a fraction of the gap. Because this approach treats new and existing aid dollars as interchangeable in filling the gap, it is potentially appropriate only for existing aid that has a similar general equalizing purpose as the new aid, not for existing aid that is earmarked for specific purposes. The full substitutability of existing and new aid funds is incorporated into the formula by calculating combined aid (new aid plus existing aid) - the ultimate bottom line for equalization results first. Hence, combined per capita aid to community $k, C A_{k}$ fills the fraction $r_{3}$ of the relative gap for equalizing communities, and all communities are, as before, guaranteed a minimum of $M$ in new aid per capita:

$$
\begin{aligned}
& C A_{k}=A_{k}+E_{k}=\max \left(M+E_{k}, r_{3} \times\left(G_{k}-G^{*}\right)\right) \\
& =M+E_{k} \text { if community } k \text { receives minimum aid, or } \\
& =r_{3} \times\left(G_{k}-G^{*}\right) \text { if community } k \text { receives equalizing aid, }
\end{aligned}
$$

where $r_{3}$ is the fraction of the gap filled by combined aid with the third approach and

$$
r_{3}=\frac{\left(T A-M \sum_{j} N_{j}+\sum_{i} E_{i} N_{i}\right)}{\left(\sum_{i} N_{i}\left(G_{i}-G^{*}\right)\right)} .
$$

Then new per capita aid, $A_{k}$, is calculated as 


$$
A_{k}=C A_{k}-E_{k}=\max \left(M, r_{3} \times\left(G_{k}-G^{*}\right)-E_{k}\right) .
$$

Note that the expression above implies that $\frac{\partial A_{k}}{\partial E_{k}}<0$ for equalizing communities.

Only a fraction of the gap is filled in any approach, as $r$ in all cases is considerably below unity. Therefore, taking existing aid outside the parentheses - as in the third approach - so that it is not multiplied by $r$ counts it dollar for dollar like new aid in filling the gap. If aid were able to fill every community's relative gap entirely - which is what foundation aid formulas used for school aid in many states do-the second and third approaches would be equivalent. But the fact that only a fraction of the gap is filled in municipal aid formulas implies that subtracting existing aid from the gap-as in the second approach-counts only a fraction $\left(r_{2}\right)$ of it in filling the gap and hence treats it inconsistently with new aid.

The third approach is able to achieve a higher degree of equalization than the first or second. When existing aid contributes to filling the gap, more of the total new aid pool is available for filling relative gaps of communities with lower existing aid and larger relative gaps. In addition, among communities receiving equalizing aid, combined aid dollars are more focused on those with larger relative gaps. The third approach also may shift the relative newaid positions of some communities that receive equalizing aid. When existing aid of some equalizing-aid communities is high enough that $E_{k}>\frac{\left(r_{3}-r_{2}\right) \times\left(G_{k}-G^{*}\right)}{\left(1-r_{2}\right)}$, they receive less new aid with the third approach than with the second approach. That is,

$$
r_{3} \times\left(G_{k}-G^{*}\right)-E_{k}<r_{2} \times\left(G_{k}-G^{*}-E_{k}\right) .
$$


More communities may receive minimum aid with the third approach than with the first and second approaches. Communities shift from equalizing to minimum aid in the third approach because their existing aid $E_{k}$ fills a fraction of their gap greater than $r_{3}$; like other minimum-aid communities, they receive more combined aid in proportion to their relative gaps than do equalizing-aid communities.

\section{Comparing the three approaches}

For a community $k$ receiving equalizing aid under all three approaches, combined aid is as follows:

$$
\begin{aligned}
& C{A_{k}}^{1}=r_{1} \times\left(G_{k}-G^{*}\right)+E_{k} \\
& C{A_{k}}^{2}=r_{2} \times\left(G_{k}-G^{*}\right)+\left(1-r_{2}\right) \times E_{k} \\
& C{A_{k}}^{3}=r_{3} \times\left(G_{k}-G^{*}\right) .
\end{aligned}
$$

Thus combined aid is proportional to the relative gap in the third approach, while communities with greater existing aid receive more combined aid in the first and second approaches compared with communities with less or zero existing aid and the same relative gaps. ${ }^{16}$

Figure 5 compares the simulated distributions of combined per capita aid using the three approaches. For these simulations, we assume the same set of policy variable values as in Scenario 1 of Table 2: a total new aid pool of $\$ 275$ million, a baseline gap of $\$ 244$, and minimum aid of $\$ 10$. The figure also shows the pattern of existing aid in Massachusetts (open circles in

\footnotetext{
${ }^{16}$ With any approach, a higher value of $r$ indicates a greater degree of equalization. However, when comparing the three approaches, $r$ cannot be considered a pure measure of equalization because $r_{2}$ is a fraction of a different (net of existing aid) gap than $r_{1}$ is, and $r_{3}$ considers the fraction of the gap filled by both existing and new aid.
} 
figure), defined for this purpose as the sum of the Commonwealth's two general-purpose municipal aid programs: additional assistance and lottery aid. While communities with larger gaps generally receive more existing aid than smaller-gap communities, the association with gaps across communities is quite loose. Across all communities, the correlation between existing aid and gap is 0.5 , and for communities with gaps above the baseline, the correlation is 0.67. ${ }^{17}$ Table 3 summarizes the aid distributions under the three approaches.

For the first approach, new aid is distributed just as in Figure 1 above-at the minimum for communities with lower gaps and directly proportional to the gap for equalizing-aid communities. However, since existing aid is not highly correlated with the gap, combined aid (diamonds in figure) is only moderately closer to being proportional to the gap than existing aid. The correlation between the amount of combined aid and the size of the gap above the baseline is 0.80 . As the table indicates, two-thirds of the 351 communities receive equalizing aid. The fraction of the gap filled by combined aid for those communities has a very wide rangefrom 25 percent to about 130 percent-because existing aid is not proportional to the gaps.

Because the second approach takes some account of existing aid, combined aid is slightly more associated with the gap, with a higher correlation of 0.84 , than it is in the first approach. The two highest-gap quintiles receive more per capita combined aid with the second approach than with the first. Three-fifths of the communities receive equalizing aid, and the

\footnotetext{
${ }^{17}$ Lottery aid per capita is distributed in inverse proportion to per capita property tax base, so it is correlated with communities' gaps; the gaps depend negatively on revenue capacity, which is measured as a function of (but not directly proportional to) per capita property tax bases (Bradbury and Zhao 2006). Additional assistance represents the remnants of an aid distribution enacted in the mid 1980s, which followed a gap-based approach like the second outlined above. However, because the school aid formula "trumped" municipal aid and faster-expanding school aid was subtracted from "gap-filling" aid, many communities were left with no additional assistance.
} 
fraction of the gap filled by combined aid for these communities lies within a narrower band than under the first approach. Because the gap net of existing aid is used in determining new aid, communities for which existing aid more than fills their gap receive minimum aid in the second approach. ${ }^{18}$

With the third approach, many communities whose gaps are relatively large receive combined aid proportional to their gaps - the combined-aid observations fall along an upwardsloping line. That is, because combined aid is the "bottom line" for the third approach, new aid moves most communities with large gaps up from wherever their existing aid had put them to a consistent fraction of their gaps. Combined aid for the two highest-gap quintiles of communities is larger with the third approach than with the other two, and the correlation between combined aid and gap is 0.91 . Almost 40 percent of communities receive equalizing aid, and for every one of them, combined aid fills 44 percent of their relative gap.

The only communities that receive equalizing aid under all three approaches are those with large relative gaps and relatively smaller existing aid. If existing aid distributions are large and/or haphazardly distributed relative to size of the current relative gap (as one might surmise is the case in Massachusetts from examining Figure 5), a number of communities that would receive equalizing aid under the first or second approaches may become "minimum-aid" communities under the third approach. ${ }^{19}$

\footnotetext{
${ }^{18}$ Hence the range of "relative gap filled by combined aid" does not exceed 100 percent for equalizing-aid communities, while it does with the first approach.

${ }^{19}$ By contrast, if the only "existing aid" is dollars distributed in the previous year through the current formula, and if there has been no change in gaps, population, or program parameters - that is, if the previous year's aid was distributed in proportion to the current year's gaps except for minimum-aid communities - then the three approaches lead to the same distribution in the second year.
} 
In sum, when some or all communities receive existing aid, it is difficult to justify the first approach, which ignores the availability of those funds entirely, unless the existing aid is earmarked for purposes not included in the "cost" measure and/or for which general revenue (capacity) may not be substituted. Similarly, the second approach may be viewed as equitable if the policymaker values existing aid in terms of objectives that are different from those used in developing the new, gap-based aid formula, and if its distribution meets those objectives.

However, if the policymaker believes that the relative gap, $\left(G_{k}-G^{*}\right)$, is the best indicator of community $k^{\prime}$ s relative current need for aid, then the appropriate indicator of a formula's "fairness" (defined as its success in "equalizing" across the chosen measure of "need") is the degree to which combined (new and existing) aid dollars are targeted in proportion to the magnitude of the relative gaps across communities. In this case, the third approach is the fairest, since the first two give different weights to existing versus new aid dollars and as a result are overly favorable to communities with more existing aid.

\section{Alternatives to Full Hold Harmless}

If a state chooses not to retain the previous year's aid or other existing aid distribution in the current year, it can completely eliminate it and start afresh, or it can ease the transition by holding harmless some fraction of existing aid and redistributing the remainder of the old aid along with the new pool through the current formula. Martinez-Vazquez and Boex (2006) recommend a phase-in approach to a new formula, which they say can be accomplished by gradually introducing the new mechanism while maintaining part of the status quo. Recall that the reason usually given for retaining the existing aid distribution in the current year is stability, 
as communities prefer to avoid any reductions in aid. "There is always a tension between program stability and targeting where the money is supposed to go" (Jabine, Louis, and Schirm 2001). Partial hold harmless presents a compromise, reducing the potential disruption from reductions in aid while shifting more funds toward the new formula.

Implementing partial hold harmless in the third approach, combined aid per capita is

$$
C A_{k}=A_{k}+\phi E_{k}=\max \left(M+\phi E_{k}, r_{4} \times\left(G_{k}-G^{*}\right),\right.
$$

where $\phi$ is the hold-harmless percentage and

$$
r_{4}=\frac{\left(T A+(1-\phi) \sum_{k} E_{k} N_{k}-M \sum_{j} N_{j}+\phi \sum_{i} E_{i} N_{i}\right)}{\left(\sum_{i} N_{i}\left(G_{k}-G^{*}\right)\right)} \text {. Because } \frac{\partial r_{4}}{\partial \phi}<0, \text { a lower hold- }
$$

harmless percentage results in filling a higher fraction of current-year relative gap with combined aid among equalizing communities. Another effect of shifting to less than full hold harmless is that combined aid is smaller for minimum-aid communities, since only the chosen percentage of existing aid is included in combined aid along with the new minimum aid. ${ }^{20}$ Consequently, the number of minimum-aid communities is likely to be smaller with partial hold harmless than with full hold harmless, leaving more funds for equalizing communities and a larger fraction of their gaps filled.

${ }^{20}$ When shifting from 100 percent to a lower hold-harmless percentage, the state policymaker must decide whether to increase minimum aid in proportion to the aid pool being distributed (the new pool plus 5 percent of existing aid when $\phi$ is 95 percent) or to keep minimum aid proportional to the truly "new" aid pool. This choice affects the minimum of combined aid, the number of minimum-aid communities, and the dollars available for equalizing communities. If minimum aid were adjusted upward to cover the average community's 5 percent loss, needier communities would bear steeper costs from partial hold harmless than (less needy) minimum-aid communities. 
Figure 6 displays the simulated distribution of per capita aid in Massachusetts with 95 percent of existing aid held harmless in the third approach, compared with 100-percent held harmless. The 5 percent of existing aid that is redistributed through the formula amounts to almost $\$ 65$ million, augmenting the $\$ 275$ million in the new aid pool by almost one quarter. Compared with 100-percent hold harmless, more communities are along the line proportional to the gap, and the line is steeper. Part of the reason that more communities are receiving equalizing aid is that some move down to the line-their new aid is not large enough to offset the loss of 5 percent of existing aid. ${ }^{21}$ In addition, because more funds are available for equalizing aid, communities moving up to the line move farther than they do under full hold harmless. Table 4 summarizes the patterns by gap quintile, indicating that, on average, the lower-gap quintiles receive less, and the two higher-gap quintiles receive more combined aid per capita with partial hold harmless than with full hold harmless. While this is not the case for all individual communities, all gap quintiles receive net new aid; that is, their average combined aid is greater than their average existing aid. Furthermore, reducing the hold-harmless percentage increases the number of communities receiving equalizing aid, raises the fraction of the gap filled by combined aid for all equalizing communities, and boosts the correlation of combined aid with gap to 0.93 .

Two examples of federal aid programs with less than full hold harmless are School Assistance in Federally Affected Areas and Community Development Block Grants, each of

${ }^{21}$ Only 23 of the 351 cities and towns receive combined aid that is smaller than their existing aid. 
which held harmless 80 percent of the previous year's aid. ${ }^{22}$ As noted, partial hold harmless involves a tradeoff between making the aid distribution more equalizing with respect to the current gap and the cost of adjustments (substantial with lower percentages held harmless, more moderate with 95 percent hold harmless) for communities that receive fewer combined aid dollars than their existing aid. ${ }^{23}$

\section{Multiple-year aid distributions}

As state funds for local aid are often limited, no aid program is likely to achieve fiscal equalization in just a year or two. In order to have a real impact on municipalities and accomplish the goal of equalization, the state government needs to have a long-term plan for the aid formula. To provide an example of the type of information a state might want to explore in developing such a plan, we simulate the dynamics of aid distributions over multiple years based on Massachusetts data and examine their evolution over time.

Five-year policy simulation

We run a five-year aid simulation under several simple assumptions, using the third approach described in Section II to hold existing aid fully harmless.

(1) The population and the gap of every community are assumed unchanged over the five years (from 2007 to 2012).

\footnotetext{
22 These formulas (and others) are described in Gonzalez (1980).

${ }^{23}$ Some formulas use hold-harmless methods other than guaranteeing a set percentage of existing aid. For example, the SCHIP program guarantees that no state's share will be less than 90 percent of its share in the preceding fiscal year, while the Canadian (provincial) equalization program uses a hold-harmless percentage based on the size of the grant under the new formula.
} 
(2) Existing general-purpose aid is held constant at its FY2007 levels.

(3) The three policy variables are assumed to have the same values for each of the five years that were examined in the earlier simulations: a total new aid pool of \$275 million, minimum per capita new aid of $\$ 10$, and a baseline per capita gap of $\$ 244 .{ }^{24}$

Figure 7 shows the distributions of the combined general-purpose aid over the five years under the above assumptions. The first-year aid distribution is identical to the one summarized in the right-hand columns (third approach) of Table 3. Table 5 summarizes the aid distribution in the fifth year.

The figure and the tables show that the five-year aid program with the assumed policy choices has a positive multiple-year effect. For equalizing-aid recipients, the fraction of the relative gap filled by combined aid rises over time, and an increasing number of communities join the equalizing-aid group over the course of the five years. Some communities are initially in the minimum-aid group not because they have small gaps, but because their existing aid is larger and fills a fraction of their relative gap that is greater than $r_{3}$. Treating existing aid the same as new aid enables communities that receive little or no existing aid but have large gaps to receive more new aid, and ultimately to catch up in terms of the filled fraction of the relative gap. Once this occurs, the large-gap, minimum-aid communities will move into the equalizingaid group. In other words, two communities with similar per capita gaps may start with rather different amounts of currently existing aid per capita in year 0 , but the new aid would level the

${ }^{24}$ As the state government puts new funds into the aid pool each year, policymakers may consider gradually lowering the baseline gap over time so that more communities would be included in the equalizing aid group. 
playing field between them over time, eliminating the differences in their combined aid. In the fifth year, combined aid is almost perfectly correlated with the gap above baseline.

Tradeoffs between short-term and long-term goals

Policymakers may face tradeoffs between short-term and long-term goals in a multipleyear aid plan. The long-term goal of the aid formula is to achieve fiscal equalization across communities. But as mentioned earlier, in the short term, some large-gap communities could be in the minimum-aid group because they already receive substantial amounts of existing aid. However, these communities could still have much larger gaps net of combined aid (in absolute terms) than some communities in the equalizing-aid group. The basic difficulty, as noted earlier, is that a constant fraction of the gap filled (and hence a constant fraction left unfilled) involves larger dollar amounts of unfilled gap for communities with larger gaps.

Facing this dilemma, some policymakers may seek solutions that allow them to direct extra aid dollars to these large-gap, minimum-aid communities up front in the first few years. One way to do this is to set minimum per capita aid higher. ${ }^{25}$ This policy option is simple, but it is not well targeted and could hurt the large-gap, minimum-aid communities in the long run, because it provides more aid to all low-gap communities and thereby causes others to take longer to catch up in terms of the filled fraction of the relative gap. As a result, these communities will stay in the minimum-aid group longer (which admittedly is a better (or less-

${ }^{25}$ Doing this could reduce the need for full hold-harmless because minimum aid also provides a certain degree of cushion against aid reduction from year to year. 
bad) place to be when minimum aid is larger), and more aid will ultimately go to less needy communities.

A second option is to have minimum aid in tiers, instead of the single aid floor in our formula. For example, one could establish a low level of minimum aid for communities with the smallest gaps and a higher level of minimum aid for communities with relatively large gaps, some of which already receive more existing aid. The drawbacks of such a "tiered minimumaid" approach are that it adds complexity to the formula and causes a discontinuity in the aid distribution at some arbitrary level of gap. A community receiving the low-level minimum aid could be very similar to another community receiving the higher-level minimum aid, with the per capita gaps of these communities differing by only a few dollars, but falling on either side of the cut-off gap level.

Policymakers could alternatively consider tiering baseline gaps to address the "absolute dollar vs. fraction" issue mentioned above. For example, if they chose two levels of baseline gap, the combined aid going to communities with gaps above the higher-level baseline gap could be a larger fraction of the relative gap than the combined aid going to communities with gaps between the two baseline gaps (with minimum aid, as before, below the lower-level baseline gap). To run this formula, policymakers would need to choose not only two baseline gaps, but also the difference between the fractions of the relative gap filled by combined aid for the two equalizing-aid groups. In practice, this tiered-baseline-gap approach may be difficult to implement, as adding two more policy variables to the formula makes it more challenging to reach a consensus among policymakers on the values of these variables. 
Another option for policymakers to consider is to create a separate "transition" aid account specifically to address the tradeoffs between the short-term and long-term goals. The state government can distribute funds from this separate account through another gap-based formula that has a zero minimum for aid and does not take account of existing aid in filling the gap (essentially the first approach described in Section II). With this add-on separate account, the new aid formula mechanism becomes a hybrid of two gap-based approaches, one considering existing aid and the other not. Policymakers would need to choose a cut-off gap (that is, a second baseline gap) in order to determine communities' eligibility for this extra aid, decide on how much funding to provide for this separate account, and consider how long the transition period should be. Like the other alternatives, this compromise between short- and long-term goals may be manageable but certainly adds more complexity to the formula mechanism.

\section{Conclusion}

This paper develops a gap-based equalization-aid formula that includes three policy variables: the total new aid pool, the minimum per capita new aid, and the baseline per capita gap. As both the conceptual analysis and the data simulations show, policymakers face tradeoffs in selecting values for these policy variables.

For the cases in which there is existing local aid that the state wishes to hold harmless for each community when implementing a new formula to distribute additional aid dollars, we introduce a new approach that is more equalizing than two "standard" approaches. The standard approaches (ignoring existing aid or subtracting it from the gap by adding it to 
revenue capacity) are more favorable to communities that receive more existing aid than to those that have the same gap and receive less or no existing aid. The new, and fairer, approach weighs new and existing aid equally in filling communities' gaps: it targets the combination of new and existing aid in proportion to the gap and thereby achieves more equalization while honoring the hold-harmless guarantee.

If state policymakers decide not to maintain existing aid distributions fully alongside a new aid program (that is, they reduce the fraction held harmless to below 100 percent), they face a tradeoff between pursuing the equalization goal aligned with the gap-based measure of need and avoiding city and town budgetary difficulties associated with reductions in aid. Through simulations, we show that the new formula approach has even greater equalizing effects over multiple years. An increasing number of communities join the equalizing-aid group, as new aid "corrects" the differences in existing aid among communities over time. Because policymakers may face tradeoffs between short-term and long-term goals, we also discuss several "compromise" solutions.

Our formula is designed to distribute (non-school) municipal aid. The foundation-aid approach used by most states for education aid is implicitly consistent with our approach, because foundation formulas are designed to fill 100 percent of the gap between each district's foundation spending amount and its local revenue capacity, so that existing and new aid are treated equivalently in filling the gap. ${ }^{26}$ If a state is considering moving away from filling the

${ }^{26}$ Put another way, the standard approach that subtracts existing aid from the gap counts only the fraction $\mathrm{r}_{2}$ of existing aid toward filling the gap, but when $\mathrm{r}_{2}=1$, all of existing aid is counted and the two approaches are equivalent. 
entire foundation gap, its policymakers should consider carefully how to account for existing school aid.

Our new formula is tailored to Massachusetts, but the framework, principles, and policy recommendations are potentially applicable to other states. Although a number of states have been using formulas to distribute aid for a fairly long time, the design of aid formulas is still a contentious subject. For example, Minnesota has modified its gap-based Local Government Aid formula many times since it was originally developed in the early 1970s. Its most recent reform effort resulted in a new formula in 2003. However, Minnesota Taxpayers Association (2003) suggests that this new formula still leaves substantial room for improvement. This paper provides policy tools that are potentially useful to such states in designing new aid formulas or improving existing aid formulas. 


\section{References:}

Bluestone, Barry, Alan Clayton-Matthews, and David Soule. 2006. Revenue Sharing and the Future of Massachusetts Economy. <http://www.curp.neu.edu/pdfs/MMA_RevenueSharing.pdf>

Bogart, William T. and Jon Erickson. 1989. “On the Design of Equalizing Grants.” Publius: The Journal of Federalism 19 (Spring), 33-46.

Bradbury, Katharine L., Helen F. Ladd, Mark Perrault, Andrew Reschovsky, and John Yinger. 1984. "State Aid to Offset Fiscal Disparities Across Communities." National Tax Journal 37:2 (June), 151-170.

Bradbury, Katharine and Bo Zhao. 2006. "Measuring Disparities in Non-School Costs and Revenue Capacity among Massachusetts Cities and Towns." Federal Reserve Bank of Boston Working Paper Series no. 06-19.

Chernick, Howard. 2004. "Fiscal equalisation between Swedish municipalities", in Fiscal Federalism in Unitary States, Per Molander (ed.), ZEI Studies in European Economics and Law, Norwell, MA, Kluwer Academic Publishers, pp. 77-100.

Downes, Thomas and Thomas F. Pogue. 1994. "Accounting for Fiscal Capacity and Need in the Design of School Aid Formulas," in John E. Anderson, ed., Fiscal Equalization for State and Local Government Finance, New York, Praeger Publishers.

Downes, Thomas and Thomas F. Pogue. 2002. "How Best to Hand Out Money: Issues in the Design and Structure of Intergovernmental Aid Formulas." Journal of Official Statistics 18:3, pp. 329-352.

Dye, Richard F. and Andrew Reschovsky. 2008. "Property Tax Responses to State Aid Cuts in the Recent Fiscal Crisis," Lincoln Institute of Land Policies Working Paper WP08RD1.

Gonzalez, Maria Elena. 1980. "Characteristics of Formulas and Data Used in the Allocation of Federal Funds." The American Statistician 34:4, 200-211.

Gottlieb. 2006. "State Aid Formulas and the Local Incentive to Chase (or Shun) Ratables." Urban Studies 43:7, 1087-1103.

Huang, Yao. 2004. "Appendix A: A Guide to State Operating Aid Programs for Elementary and Secondary Education." In J. Yinger, ed., Helping Children Left Behind: State Aid and the Pursuit of Educational Adequacy, Cambridge, MA, MIT Press, pp. 331-352. 
Jabine, Thomas, Thomas A. Louis, and Allen L. Schirm. 2001. Choosing the Right Formula: Initial Report, Washington, DC, National Academy Press.

Ladd, Helen F., Andrew Reschovsky, and John Yinger. 1991. Measuring the Fiscal Condition of Cities in Minnesota. Report submitted to the Legislative Commission on Planning and Fiscal Policy (April).

Ladd, Helen F. and John Yinger. 1994. “The Case for Equalizing Aid.” National Tax Journal 47:1, 211-24.

Louis, Thomas A., Thomas B. Jabine, and Marisa A. Gerstein. 2003. Statistical Issues in Allocating Funds by Formula, Washington, DC, The National Academies Press.

Martinez-Vazquez, Jorge and Jameson Boex. 2006. The Design of Equalization Grants: Theory and Applications, World Bank Institute.

Martinez-Vazquez, Jorge and Bob Searle. 2007. Fiscal Equalization: Challenges in the Design of Intergovernmental Transfers, New York, Springer.

Municipal Finance Task Force. 2005. Local Communities at Risk: Revisiting the Fiscal Partnership Between the Commonwealth and Cities and Towns.

$<$ http://www.mapc.org/Municipal_Finance_Task_Force/Executive\%20Summary.pdf>

Massachusetts Municipal Association. 2006. "Our Communities and Our Commonwealth: Partners for Progress and Prosperity."

$<$ http://www.mma.org/images/stories/NewsArticlePDFs/mma_news/mma_partnership_ principles.pdf>

Massachusetts Taxpayers Foundation. 2005. Municipal Financial Data: 35th Edition. $<$ http://www.masstaxpayers.org/data/pdf/reports/mtf35t 1.pdf >

Massachusetts Taxpayers Foundation. 2006. "The Long-Term Mismatch Between Available Resources and Important State Priorities: A Five-Year Fiscal Analysis." $<$ http://www.masstaxpayers.org/data/pdf/reports/Five-Year\%20Fiscal\%20Analysis.pdf>

Minnesota Taxpayers Association. 2003. "Monday Morning Quarterbacking LGA Reform." Fiscal Focus, 29:3 (May-June).

Spencer, Bruce D. 1982. “Technical Issues in Allocation Formula Design.” Public Administration Review (November/December), 524-529.

Yinger, John. 1986. “On Fiscal Disparities across Cities.” Journal of Urban Economics 19, 316-337. 
Figure 1. Aid Distribution through the Basic Formula

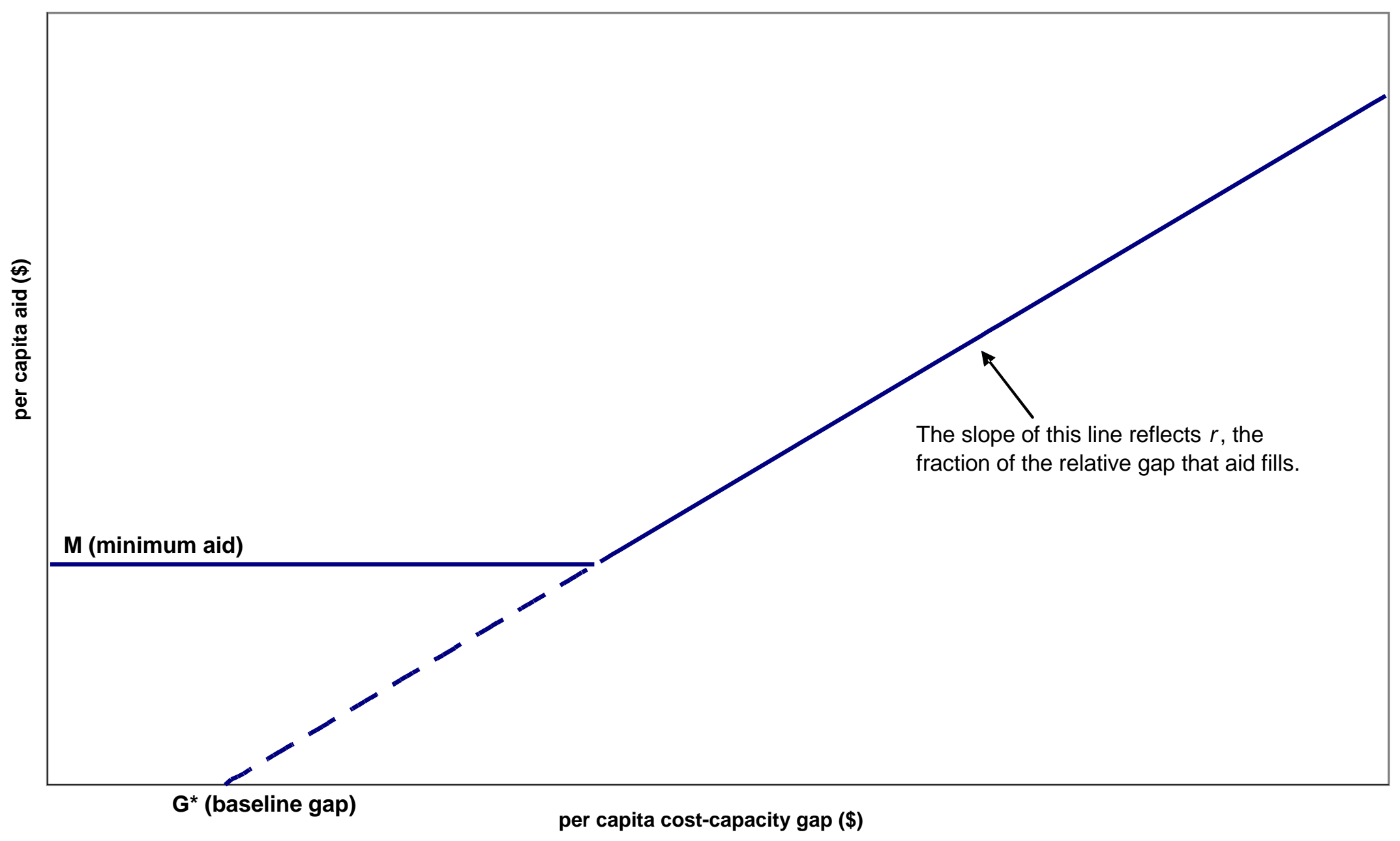


Figure 2. The Impact of Changing the Total New Aid Pool on Aid Distribution

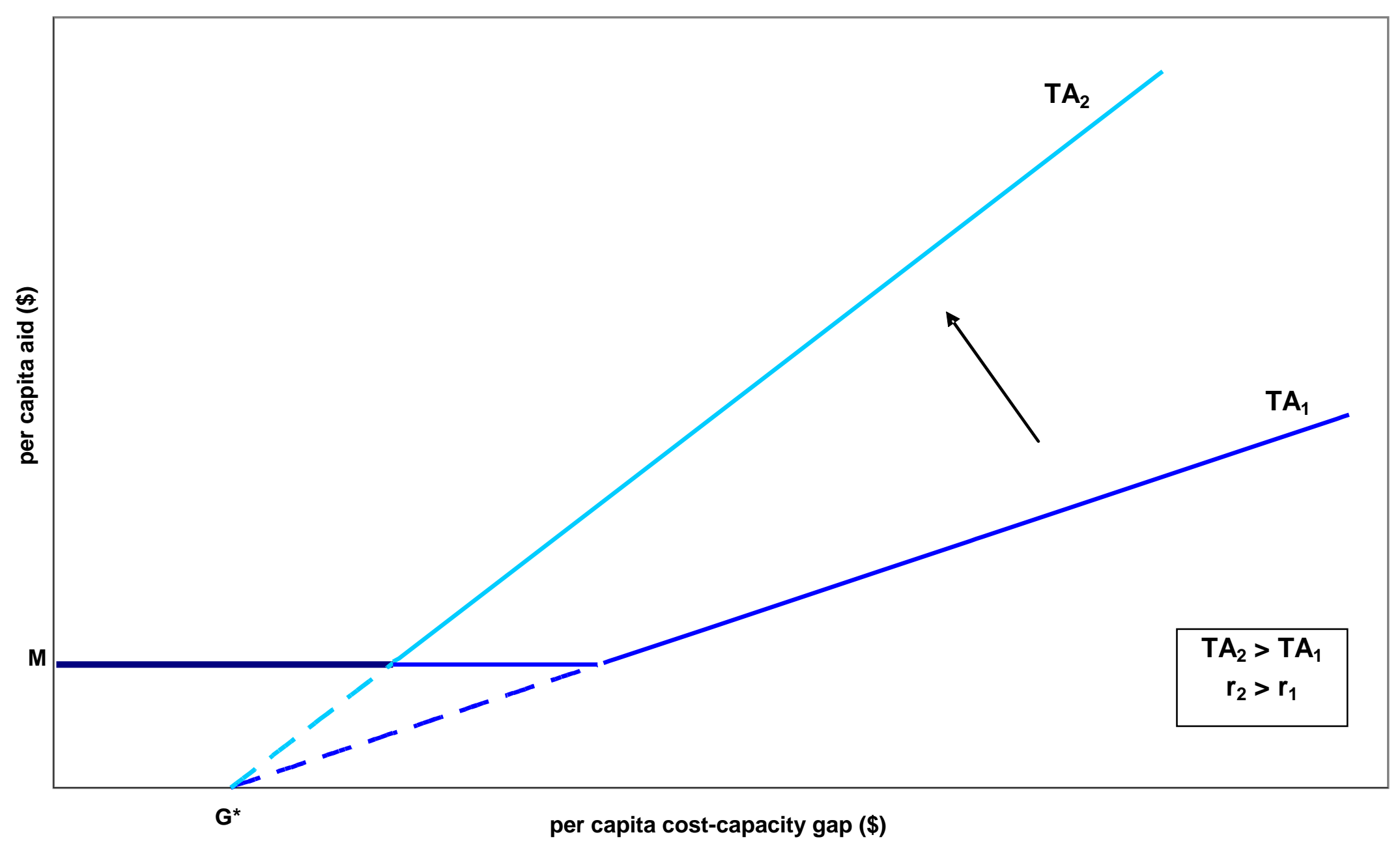


Figure 3. The Impact of Changing Minimum Aid on Aid Distribution

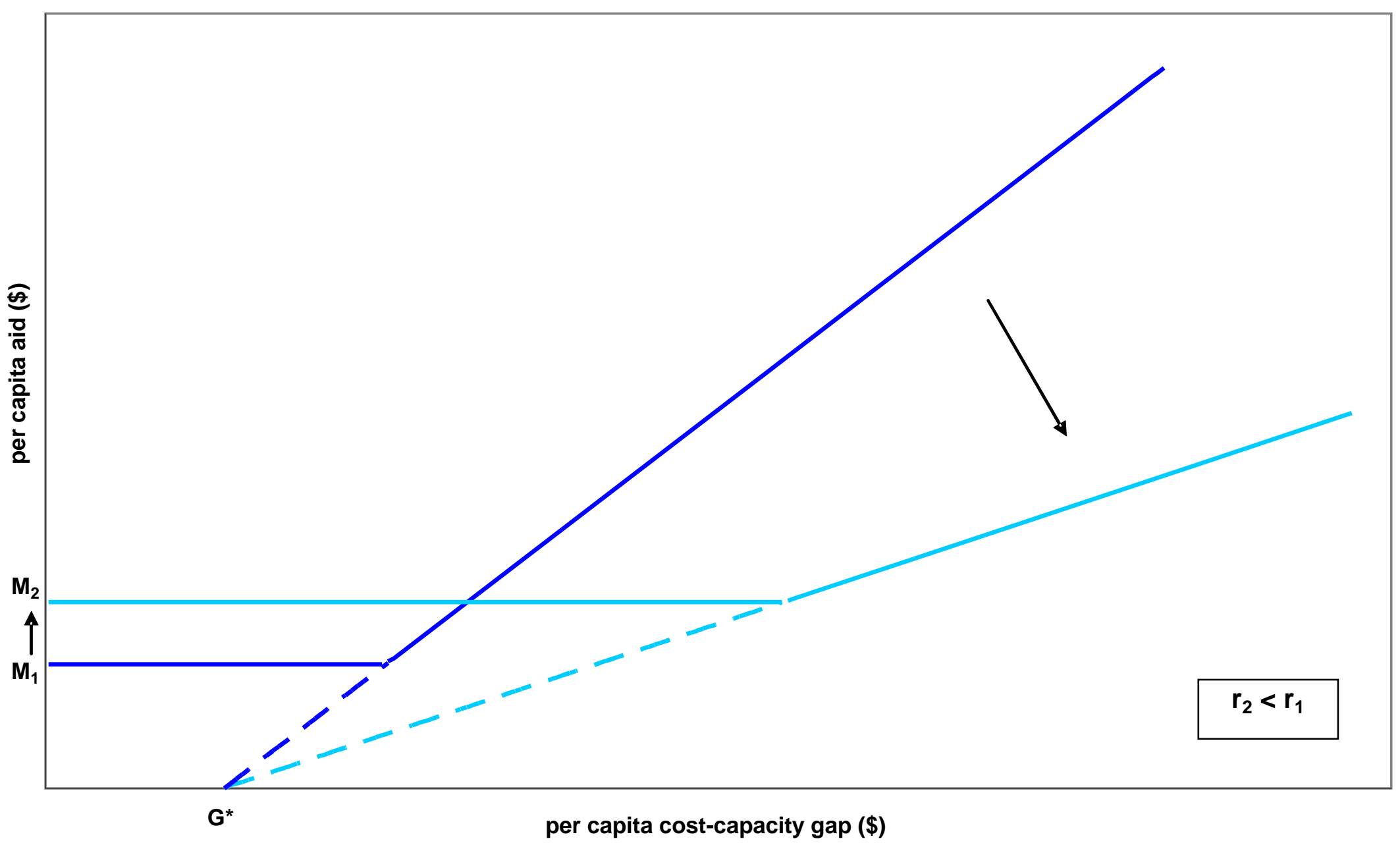


Figure 4. The Impact of Changing the Baseline Gap on Aid Distribution

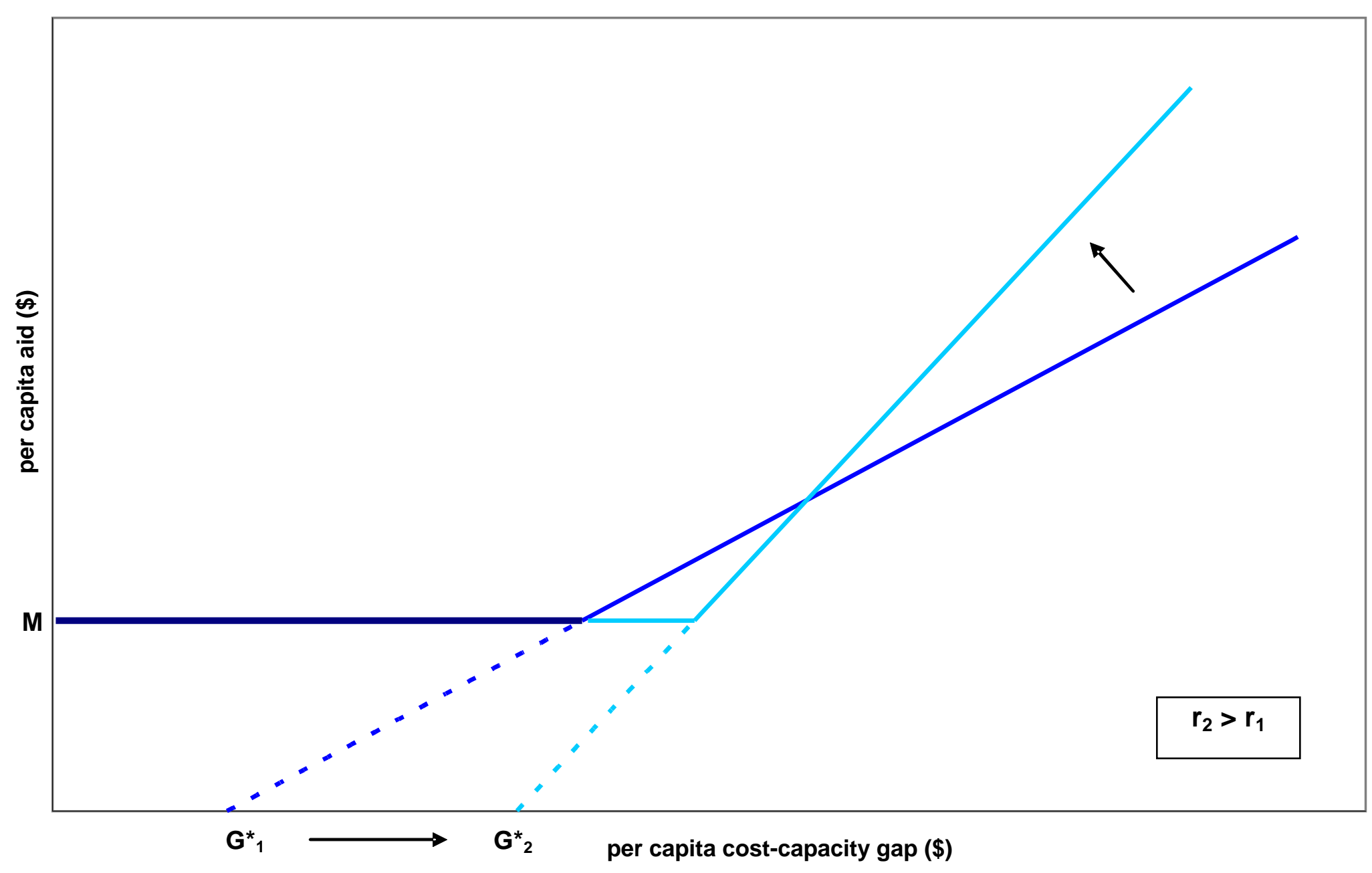


Figure 5. Distribution of Per Capita Aid, Comparing three approaches

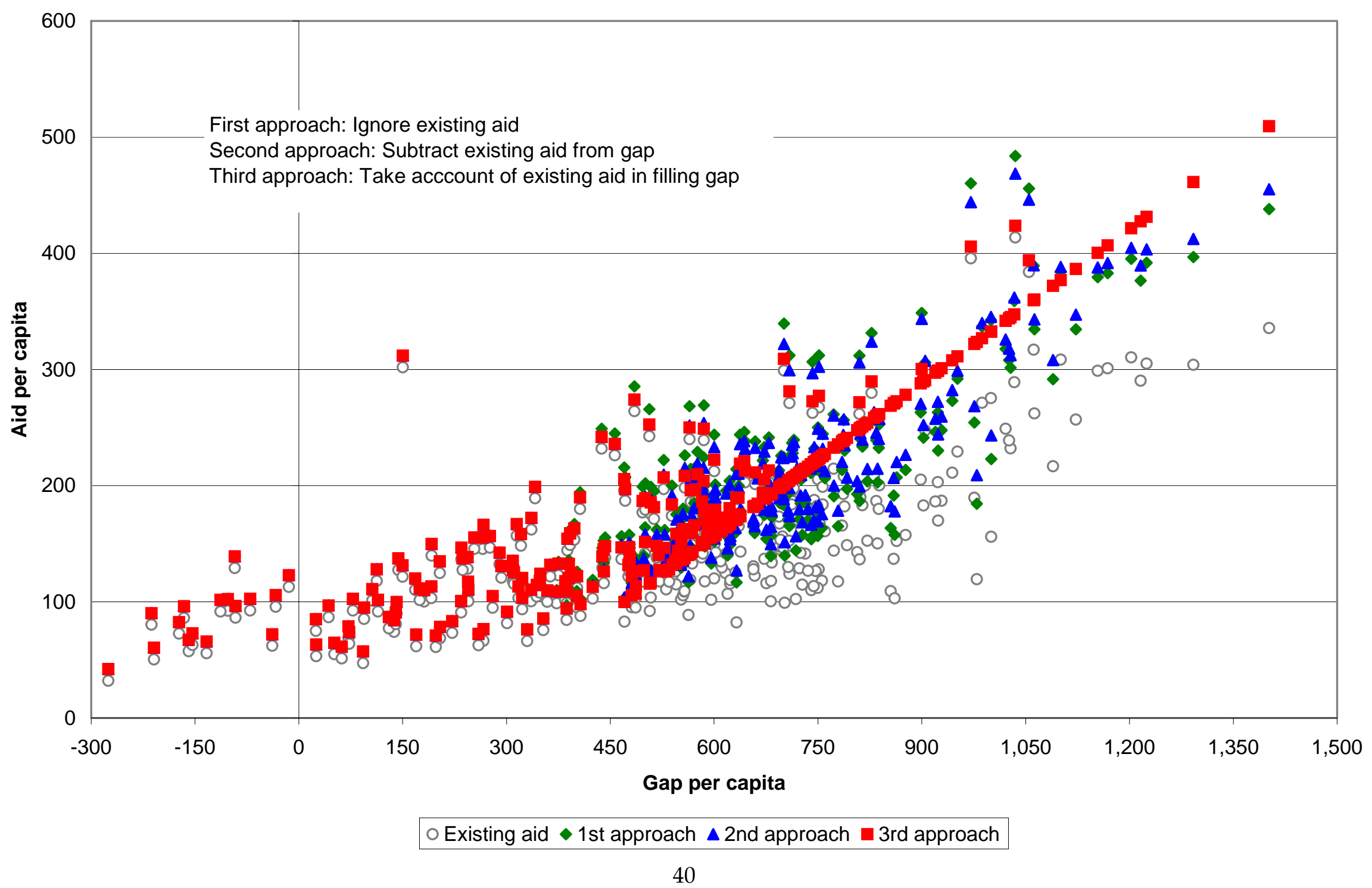


Figure 6. Distribution of Per Capita Aid, Comparing $95 \%$ and $100 \%$ Hold Harmless

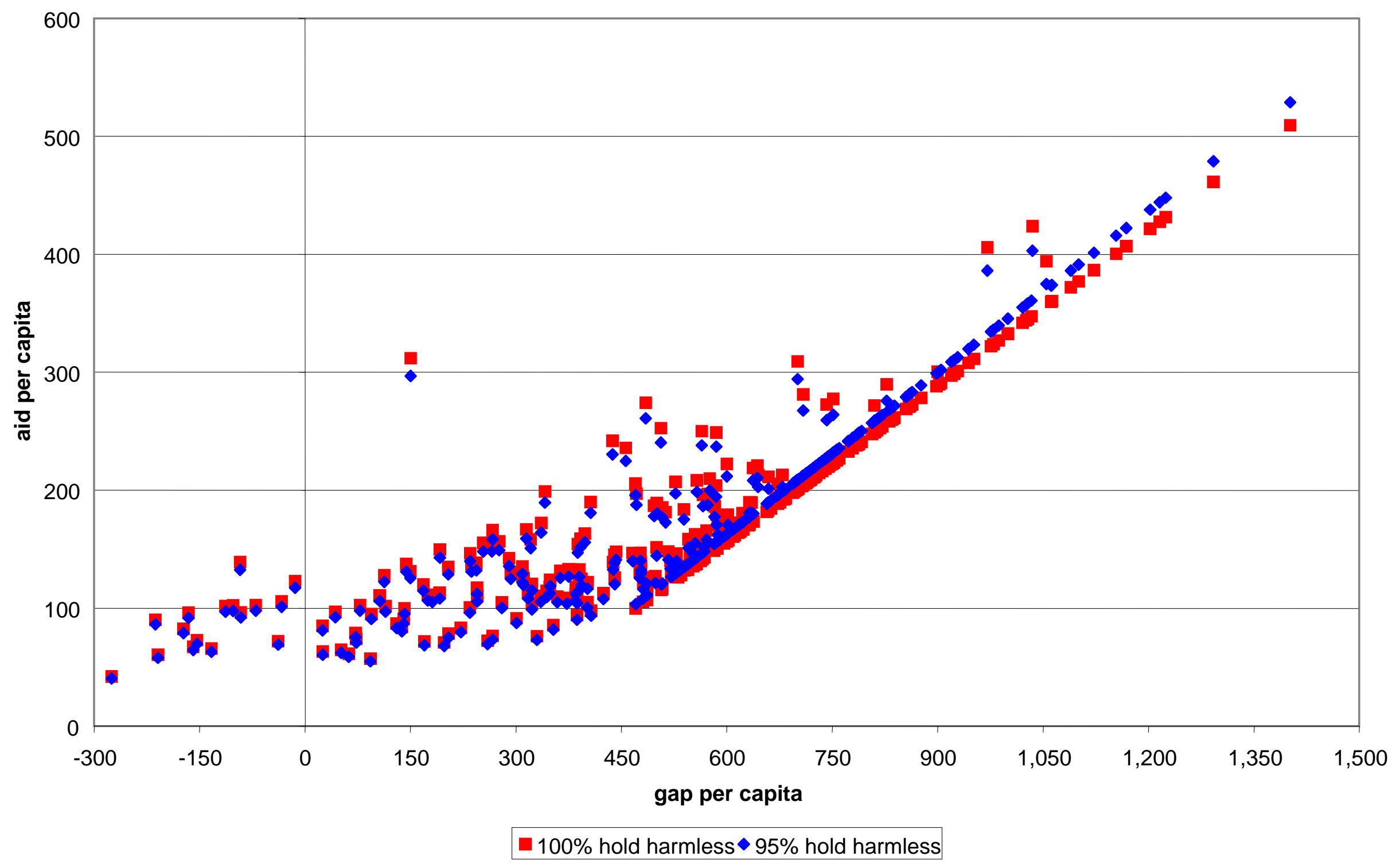


Figure 7. Distribution of Per Capita Combined Aid over Five Years (Third Approach)

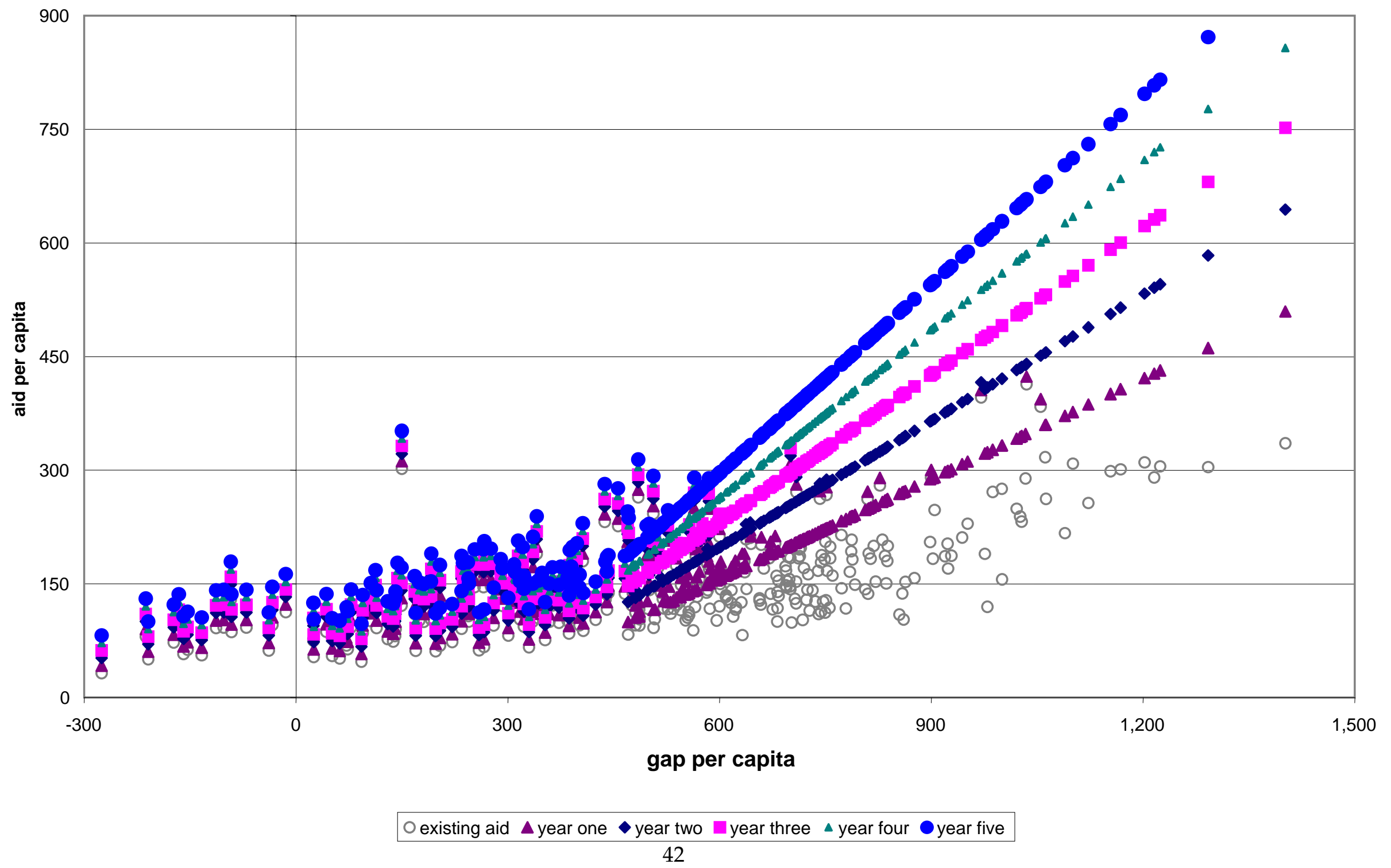


Table 1. Summary Statistics of Per Capita Costs, Revenue Capacity, and Gap for Massachusetts Cities and Towns in 2005

\begin{tabular}{lccc} 
& Municipal Costs & $\begin{array}{c}\text { Non-School Local } \\
\text { Revenue Capacity }\end{array}$ & $\begin{array}{c}\text { Cost-Capacity } \\
\text { Gap }\end{array}$ \\
\hline Mean & 1,150 & 864 & 268 \\
Median & 1,130 & 604 & 545 \\
Maximum & 2,030 & 13,450 & 1,402 \\
Minimum & 836 & 94 & $-12,451$ \\
Standard Deviation & 155 & 1,112 & 1,132 \\
\hline
\end{tabular}

Source: Authors' calculations based on methodology described in Bradbury and Zhao (2006) 
Table 2. The Impact of Changing Policy Variable Values on Aid Distributions

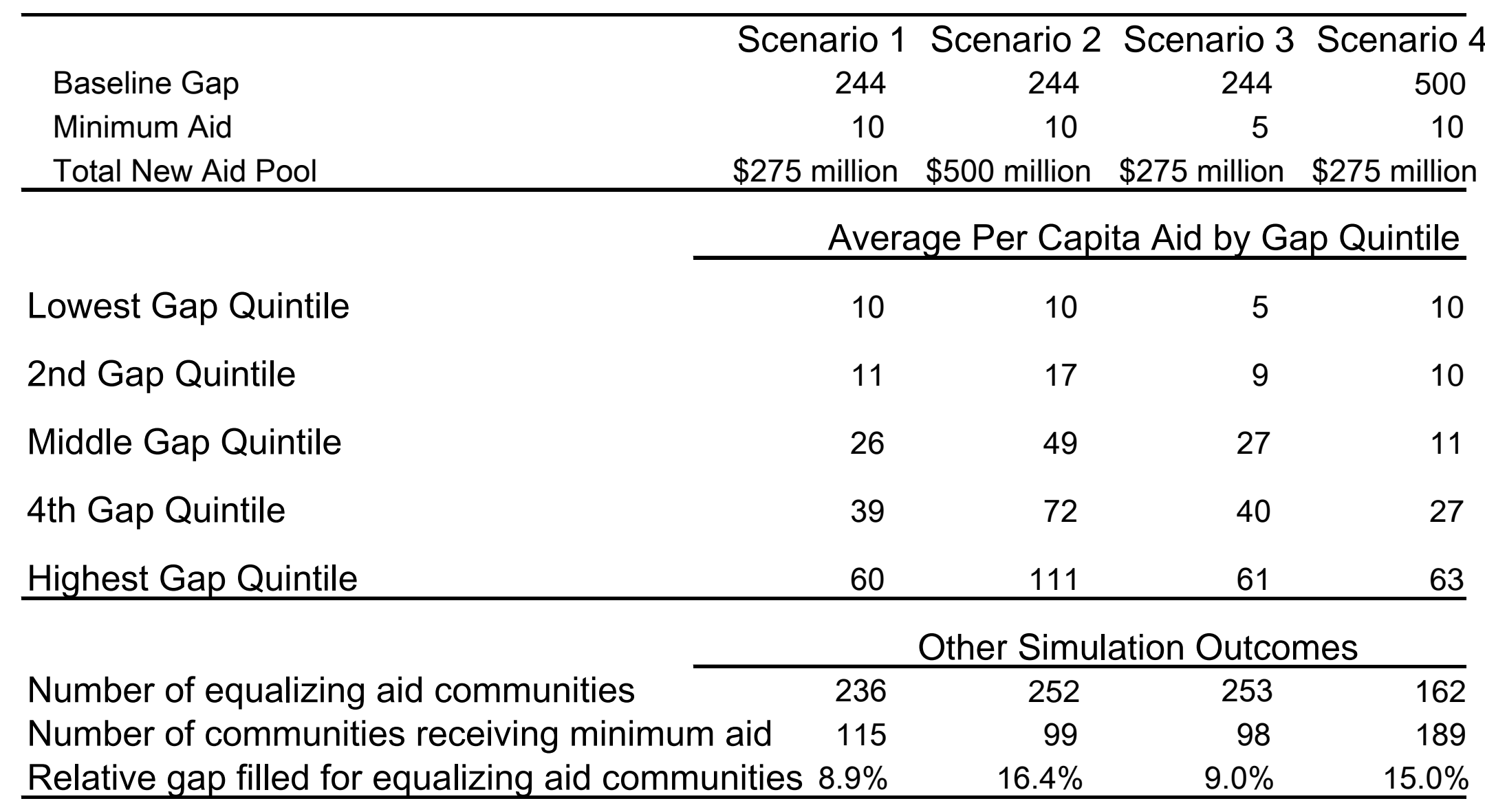


Table 3. Summary of Aid Distribution, Three Approaches, 100 Percent Hold Harmless

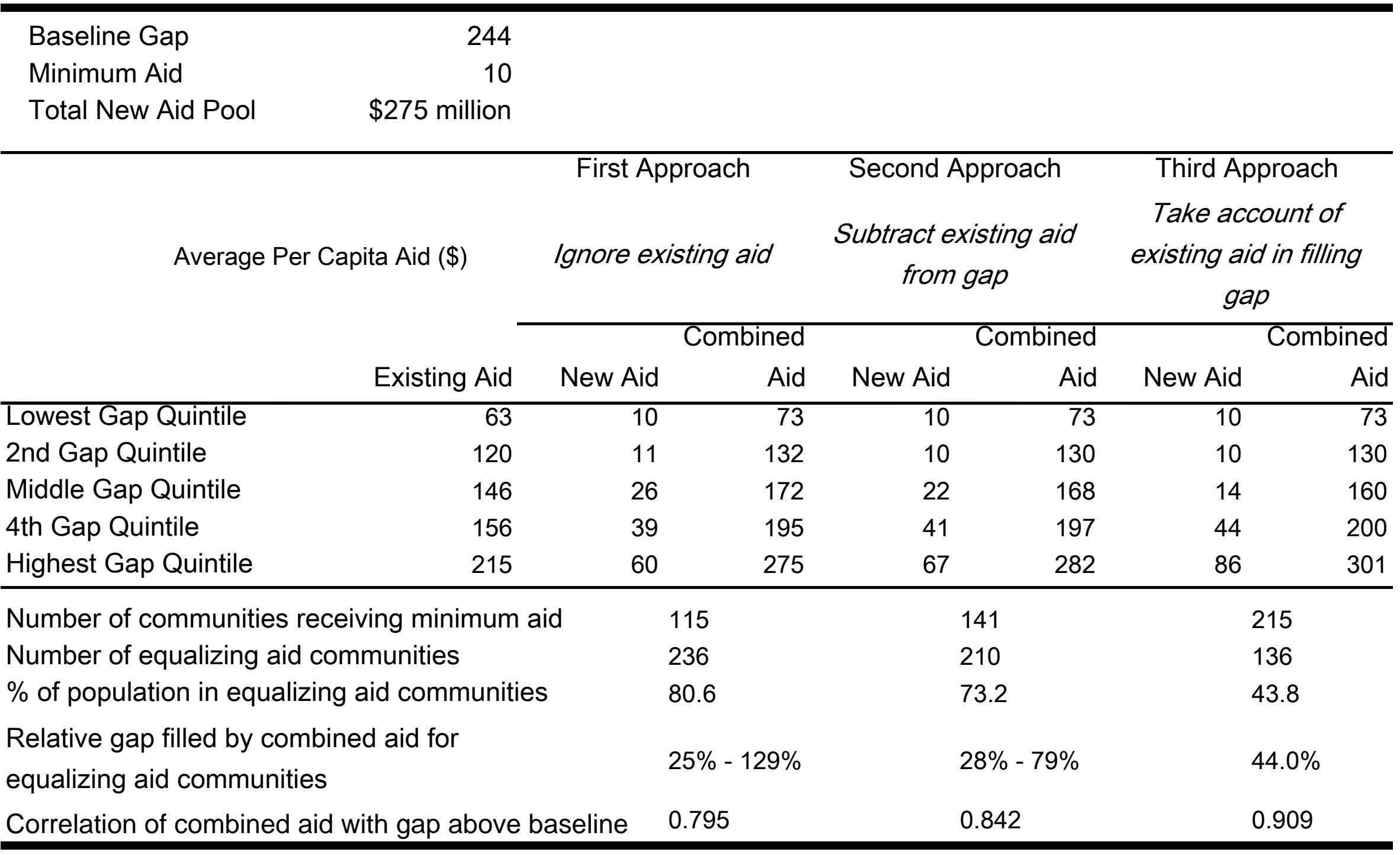


Table 4. Summary of Aid Distribution with 95 Percent Hold Harmless

Using the Third Approach: Take Account of (95\% of) Existing Aid in Filling Gap

\begin{tabular}{|c|c|c|c|}
\hline Baseline Gap & 244 & \multirow{3}{*}{\multicolumn{2}{|c|}{ plus $\$ 64.9$ million existing aid }} \\
\hline Minimum Aid & 10 & & \\
\hline \multirow[t]{3}{*}{ Total New Aid Pool } & $\$ 275$ million $p$ & & \\
\hline & & \multicolumn{2}{|c|}{ Average Per Capita Aid } \\
\hline & $\begin{array}{r}\text { Existing Aid } \\
(100 \%)\end{array}$ & New Aid & Combined Aid ${ }^{*}$ \\
\hline Lowest Gap Quintile & 63 & 10 & 70 \\
\hline 2nd Gap Quintile & 120 & 10 & 124 \\
\hline Middle Gap Quintile & 146 & 18 & 157 \\
\hline 4th Gap Quintile & 156 & 56 & 204 \\
\hline Highest Gap Quintile & 215 & 105 & 310 \\
\hline \multicolumn{3}{|c|}{ Number of communities receiving minimum aid } & 196 \\
\hline \multicolumn{3}{|c|}{ Number of equalizing aid communities } & 155 \\
\hline \multicolumn{3}{|c|}{$\%$ of population in equalizing aid communities } & 47.2 \\
\hline \multicolumn{3}{|c|}{ Relative gap filled by combined aid for equalizing aid communities } & $45.7 \%$ \\
\hline \multicolumn{3}{|c|}{ Correlation of combined aid with gap above baseline } & 0.934 \\
\hline
\end{tabular}

* Combined aid $=$ New aid $+95 \%$ of Existing aid 
Table 5.Summary of Year Five's Aid Distribution Using the Third Approach: Take Account of Existing Aid in Filling Gap

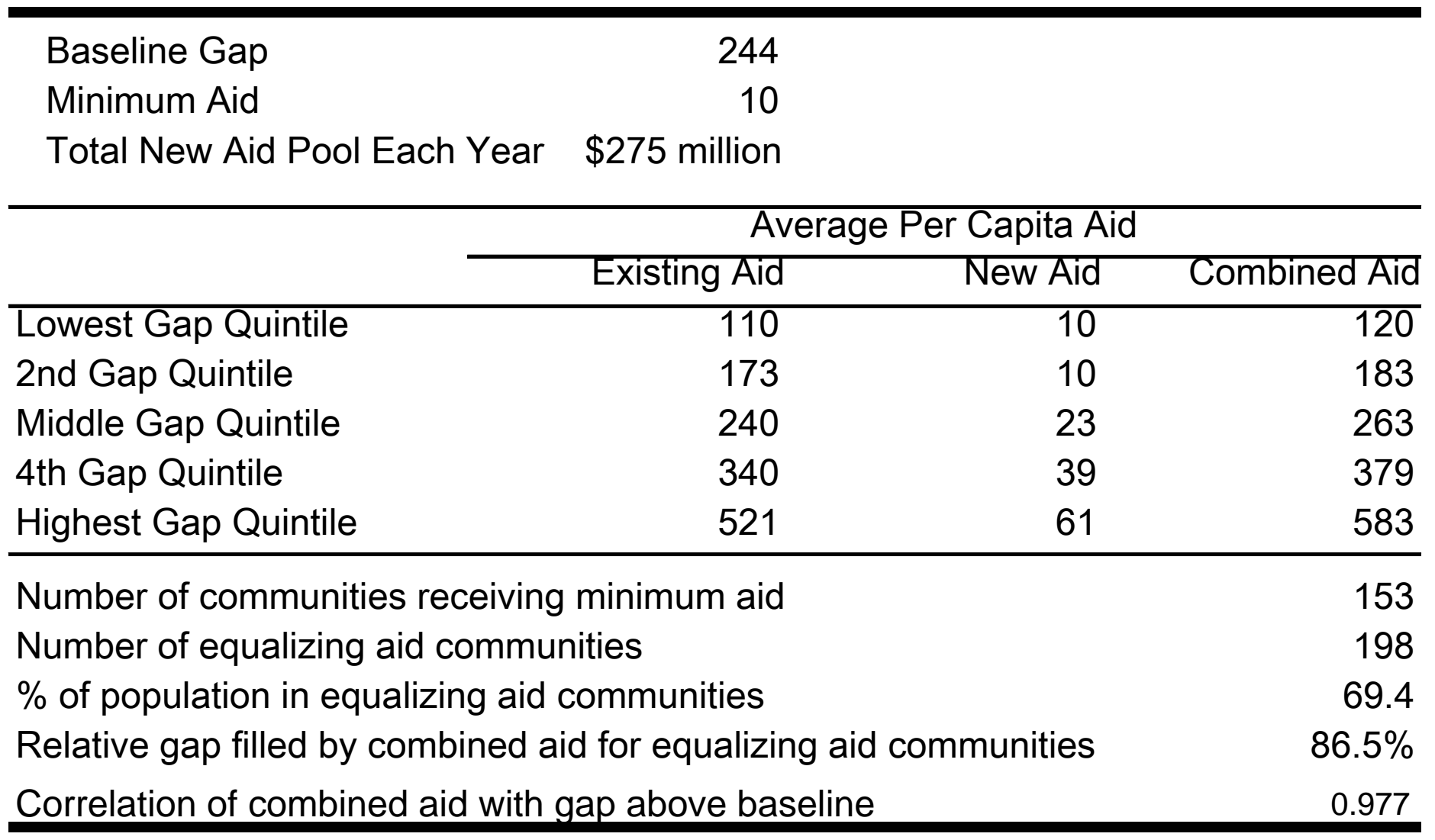

